\title{
Performance Measures for the Analysis of Rural Public Transit in Alabama
}

\author{
Michael Anderson, Ph.D., P.E., and Tahmina Khan \\ University of Alabama at Hunstville
}

\begin{abstract}
As rural public transit systems are vital to the livelihood of rural Americans, improving the operations of these systems is the focus of this work. The use of performance measures to evaluate operation is essential to maintain growth and avoid becoming stagnant. The main goal of this study was to examine existing performance measures (PM) and modify them to allow for comparison of performance among rural transit agencies in Alabama. The tasks presented in this paper are a review of performance measures, data collection, and data analysis for agencies in Alabama. The report concludes that performance measures can be developed that balance external factors in the analysis and allow for a fair comparison of agencies.
\end{abstract}

\section{Introduction}

Continually improving performance is necessary to avoid becoming stagnant or obsolete. Recently, the Transit Cooperative Research Program (TCRP) published Report 136, "Guidebook for Rural Demand-Response Transportation: Measuring, Assessing, and Improving Performance," to serve as a typology for rural demand-response systems, identify factors that influence performance, and quantify performance improvements from specific actions.

The low density in rural America, where only 17 percent of the nation's population lives in 75 percent of the nation's land area, makes the provision of transit particularly challenging (Carsey Institute 2006). The trend nationally is for the "aging" of the rural population, influenced by migration patterns away from rural America to urban America for younger people and the growth in the over-50 age group, both by total population and percent, in many rural locations (Ellis and McCollom 2009). In rural locations, access to health care and basic necessities is complicated by distance, terrain, and a population facing increased mobility challenges. This is where rural public transit systems fill mobility gaps.

As rural public transit systems are vital to the livelihood of rural Americans, improving the operation of these systems is the focus of this project. The work was stimulated by the publication of TCRP Report 136, which provides guidance into performance measures 
that were used to evaluate rural transit systems. Data to support the analysis presented in the guide were collected from the Alabama Department of Transportation and from specific agencies to determine the current levels of performance as the guide indicates. The measures presented in the guide were then modified to allow comparisons across rural transit agencies in Alabama.

The main purpose of the study was to formulate a new methodology that eliminates the influences of uncontrollable factors, thus standardizing the performance measures defined in TCRP Report 136 to make a better comparison among different rural transit systems in Alabama. The objectives were to examine published performance measures and modify them to allow for comparison of performance among rural transit agencies in Alabama. The tasks presented in this report are a review of performance measures in the TCRP Report 136 and other sources, data collection, and data analysis for agencies in Alabama. The report concludes that performance measures can be developed that balance external factors in the analysis and allow for a fair comparison of agencies.

\section{Literature Review}

Literature related to defining the proper performance measures for rural transit that allow for comparison of different systems and the development of peer grouping methodology was reviewed and summarized.

\section{Performance Measures in Rural Transit}

A dissertation by Stephanedes (1979) on performance indicators and policy evaluation in rural transit proposed a list of 32 rural performance measures that reflect six specific conditions such as output, effectiveness, efficiency, cost-effectiveness, quality, and impact. Later, Radow and Winters (n.d.) stated four ways to measure rural transit performance: effectiveness, efficiency, quality, and impact, and described how rural transportation providers face unique challenges compared to urban transit systems, and how fixed route systems are different from demand responsive service. A paper by Kosky (2007) indicates selecting proper performance measures depends on data availability, reliability, and cost of collection, while noting that the key is simplicity and minimal overlapping. It presents eight key elements to measure system performance (both efficiency and effectiveness), including total expenses, variable expenses (i.e., fuel costs, maintenance, insurance, and employee salaries), vehicle hours, passengers, miles and number of vehicles, and a number of ways to look at the relationships between these numbers as particular ratios of key elements (Kosky 2007).

As presented by Reilly et al. (1998), the main goal of rural demand responsive transportation (DRT) should be broken down to a small number of objectives based on data availability and data collection costs that are measured by clearly defined performance statistics so that the resource limitations of a system do not preclude an effective evaluation process. Reilly proposed a number of financial and non-financial indicators and describes how the performance evaluation process should be carried out (Reilly et al. 1998).

TCRP Report 165, "Transit Capacity and Quality of Service Manual," classifies demand responsive measures into two groups such as measures of availability (response time, service span, and service coverage) and measures of comfort and convenience (reliability, 
travel time, and no-shows) (Kittelson \& Associates et al. 2013). The performance of general DRT varies in terms of its productivity and depends on numerous factors such as size of the service area and its characteristics, locations of trip generators, and nature of trip demand that are quite similar to the factors mentioned in TCRP 136.

\section{Categories of Performance Measures in Urban Transit}

Upon investigating traditional transit performance measures in TCRP Report 88, "A Guidebook for Developing a Transit Performance-Measurement System," 10 different categories of performance measures were summarized:, service delivery, community impacts, travel time, safety and security, maintenance and construction, economics, capacity, paratransit, and comfort (Cottrell and James 2009). One of the reviewed papers demonstrates how some Transit Performance Measures (TPMs) related to accessibility, mobility, and economic development recommended by the Performance-Based Planning Manual across all modes can be extracted from the bus dispatch system data (consisting of automatic vehicle location, communications, automatic passenger counters, and a central dispatch center) and can assist a transit agency in improving the quality and reliability of its service, leading to improvements for customers and operators alike (Bertini and El-Geneidy 2003).

\section{Performance Measures in Funding Allocation Formulas}

For allocating subsidies to rural public transit, Evans proposes an allocation formula applying equalization models that incorporate elements of cost (cost per trip or cost per mile), need (proportion of households in the service area), and performance (number of trips or passenger miles per unit of subsidy). A methodology in which funding was awarded based on population (proportional to population) and patronage (proportional to their subsidy per passenger trip) could be a practical way of allocating subsidies (Marshment 1998). To allocate funding, a performance index, $\mathrm{Pl}$, was developed that proposed the use of weighted performance rating that is a function of revenue/cost $(\mathrm{R} / \mathrm{C})$ ratio, annual trips per capita and new trips per capita (Sousa and Miller 2005). Karlaftis and Sinha's paper (1997) evaluates whether subsidies have had differential performance impacts based on the type of operation and subsidy source. The five measures used in Karlaftis and Sinha's study to capture the efficiency and effectiveness are revenue vehicle miles per employee, revenue vehicle miles per vehicle, revenue vehicle miles per operating expense, passengers per service area population, and passengers per vehicle. It concludes that subsidies from different sources (federal or state and local) have different effects on the performance of different types of paratransit systems (differentiated on the basis of whether they are publicly or privately operated) (Karlaftis and Sinha 1997).

\section{Peer Comparison Methodologies}

When comparing transit operation in various cities, an evaluation must consider the differences in urban form and land use, population, employment distribution, topography and climate, and structure variables accordingly to minimize these effects where variables must be disaggregated by areas of the metropolitan region that distinguish between transit service in the central city and in suburban areas. To identify variables for characterizing level of service into the three major components of quantity (the supply), quality (how good the service is), and cost/revenue (deals with economic factors though depends on 
quantity and quality), Allen and Cesare (1976) concentrated on the checklist of about 45 attributes (referred to as characteristics or variables such as route density, passenger density, and operating ratio) plus the corresponding performance measures selected by a cooperative process (agreed upon by legislature, transportation agencies and the citizen's groups that combines the operator's experience, the state's research and planning capabilities, the legislature's policy making process, the local citizen's needs and desires) that best reflects the mass transportation objectives of the community and contributes to transit level of service described as quality, quality, and cost/revenue (Allen and Cesare 1976).

One of the earlier studies used z-scores of each system on each of the selected performance measures and a ranking scale developed by summing the selected indicator Z-scores for each system called as ZSUM, to indicate the overall performance of a bus system (Fielding and Anderson 1983). Data Envelopment Analysis (DEA) methodology was used in earlier and recent studies to estimate relative scores in efficiency and effectiveness of various transit systems and compare individual systems to their peers in multiple performance measures (Arman, Labi and Sinha 2012; Ferronatto, Lindau and Fogliatto 2009; $\mathrm{Fu}$, Yang and Casello 2007; Chu, Fielding and Lamar 1992). Principal Component Analysis (PCA) based indices take into account both efficiency and effectiveness leading to more reliable scores and perform better on data sets where variables are highly correlated (Ferronatto, Lindau and Fogliatto 2009).

Ryus et al. (2011) focuses on the process used to identify peer-grouping factors, followed by determining groups of transit agencies that operate with similar external constraints and that provide similar types of service. Data were developed (or attempted to be developed) for each potential peer-grouping factor for each transit agency reporting to the National Transit Database (NTD). The factors were then evaluated based on variation between region or transit agencies, data availability, ease of maintenance, and existence of an alternative factor. Factors such as service area type, proximity, population density, percent low income, state capital, vehicle miles operated etc., are used to determine which potential peer agencies are most similar to the target agency. Individual likeness scores (the percentage difference between a potential peer's value for the factor and the target agency's value) determined for each individual screening and peer-grouping factor, can be used to calculate a total likeness score, where a score of 0 indicates a perfect match between two agencies (and is unlikely to ever occur) and a score of 10 means not at all alike (Ryus et al. 2011).

$$
\text { Total likeness score }=\frac{\text { Sum (screen factor scores })+ \text { Sum }(\text { peer grouping factor scores })}{\text { Count }(\text { peer grouping factors })}
$$

To form a peer group, an agency would normally use the 8 or 10 agencies with the lowest total likeness scores and at least 4 peers are recommended at a minimum, to ensure an adequate basis for comparing performance results (Ryus et al. 2011).

The Florida peer selection process attempts to identify comparable transit systems through a point scoring system with the following eight measures: (Gan, Ubaka, and Zhao 2002): 
- Service area population density

- Revenue miles

- Average speed

- Service area population

- Vehicles operated in maximum service

- Passenger trips

- Revenue hours

- Total operating expense

The first three variables are considered primary, and the others are secondary. Under the scoring system, primary variables are given extra points. The performance of each of the potential non-Florida peers is compared with the average of the Florida systems for each of the eight measures. A peer receives one point for each measure for which it is within one standard deviation of the Florida system mean. One-half point is given for each measure that falls between one and two standard deviations from the Florida system mean. The scoring system can also be based on percentage rather than standard deviation. In the percentage-based method, a peer receives one point for each measure for which it was within 10 percent of the Florida system mean. One-half point is given for each measure that falls between 10-15 percent from the Florida system mean. In both cases, an extra one-half point is given for each of the three primary measures (Gan, Ubaka and Zhao 2002).

Overall, there are many mechanisms to evaluate rural transit performance, which generally focus on a few main data elements and analysis trends. This study was to develop a simplified methodology that should reflect and comply with the guidance of TCRP Report 136, "Guidebook for Rural Demand-Response Transportation: Measuring, Assessing, and Improving Performance" (Ellis and McCollom 2009) and can be adapted easily by using readily available data.

\section{Data Collection}

This section discusses the data that were collected to perform the evaluation of the performance measures for Alabama's rural transit systems. The data included information about the transit systems currently operating in Alabama and the counties they serve. The data of these agencies are required to be submitted to the Alabama Department of Transportation (ALDOT) on a quarterly basis and corresponding performance measures are used to track individual agency performance. Finally, the section presents other, non-controllable factors that might influence transit performance in the areas where the systems operate. These non-controllable factors are used later to compare system operation among providers.

At the time of this report, there were 29 transit systems operating in 50 of Alabama's 67 counties, with the majority being single-county operations. Each of the transit systems submits certain data/performance measures variables to ALDOT on a quarterly basis. 
Using the data submitted by the agencies, a preliminary list of performance measures was established using guidance from the ALDOT and reviewed literature. The performance measures along with the variables are shown in Table 1.

TABLE 1. Performance Measures (PM)

\begin{tabular}{|l|l|}
\hline \multicolumn{1}{|c|}{ Measures/Key Ratios } & \multicolumn{1}{c|}{ Equations Using Data / Performance Measures Variables } \\
\hline Productivity (defined below) & Passenger trips / vehicle hour \\
\hline Operating cost per vehicle hour & (Operating + administrative cost) / vehicle hour \\
\hline Operating cost per vehicle mile & (Operating + administrative cost) / vehicle mile \\
\hline Operating cost per passenger trip & (Operating + administrative cost) / passenger trip \\
\hline Average passenger trip length & Total passenger miles / total number of trips \\
\hline Average travel time & Total passenger travel time / total number of passenger trips \\
\hline Hourly utilization & Passenger hours / vehicles hours \\
\hline Mileage utilization & Passenger miles / vehicle miles \\
\hline Operating cost recovery ratio & Revenue / operating cost \\
\hline
\end{tabular}

It must be noted that the data from the quarterly reports submitted to ALDOT contained discrepancies that needed to be removed to obtain accurate performance measures. For example, vehicle miles (pull-out to pull-in, including deadhead miles and corresponding to accumulating vehicle hours, as per TCRP 136) were sometimes recorded as very large in comparison to passenger miles (sum of all passenger trip length that is measured from pickup to drop-off location, as per TCRP 136) and sometimes reported as less than passenger miles. Additionally, there were discrepancies in the revenue and cost values as charges were incurred in one quarter and the revenues were recorded in another.

\section{Problem Statement}

In reviewing the performance measures, there were some wide discrepancies across the transit agencies in the state. Table 2 shows the performance measures with average, best, and worst performance for the 29 agencies in Alabama.

TABLE 2.

Performance Measures Values

(Average, High and Low), Alabama Transit Agencies

\begin{tabular}{|l|r|r|r|}
\hline \multicolumn{1}{|c|}{ Measures/Key Ratios } & Average & \multicolumn{1}{c|}{ Best } & \multicolumn{1}{c|}{ Worst } \\
\hline Productivity (defined below) & 2.81 & 7.14 & 0.90 \\
\hline Operating cost per vehicle hour & 28.18 & 12.11 & 47.99 \\
\hline Operating cost per vehicle mile & 1.93 & 0.97 & 3.85 \\
\hline Operating cost per passenger trip & 12.40 & 3.19 & 26.96 \\
\hline Average passenger trip length & 5.36 & 1.73 & 16.46 \\
\hline Average travel time & 1.75 & 0.11 & 42.27 \\
\hline Hourly utilization & 2.16 & 42.47 & 0.10 \\
\hline Mileage utilization & 0.81 & 1.07 & 0.46 \\
\hline Operating cost recovery ratio & 0.63 & 1.58 & 0.15 \\
\hline
\end{tabular}

These performance measures and results for the transit agencies in Alabama highlight the differences in operations throughout the state. For example, productivity (the measure of passenger trips per vehicle hour), which indicates how often the vehicles are carrying multiple passengers to similar destinations, ranges from $0.90-7.14$. From an outsider's 
perspective, it could be concluded that agencies with higher than average productivity would use superior scheduling and dispatching skills as compared to agencies with lower productivity values. A similar statement could be made for all the performance measures; for example, the agencies with lower operating cost per passenger trip would be seen as superior to agencies with higher operating cost per passenger trip.

However, when attempting to compare across agencies, there are several factors that need to be examined that are outside agency control. These variables were considered important, as they represented a normalization or equalization of the performance measures. For example, an agency in a very sparsely-populated area might have a lower productivity value simply due to the fact there are fewer people in the area to serve. Similarly, an agency might have a higher operating cost per passenger trip due to offering service in a larger county where trips might tend to be longer as locations are spaced out over a wider distance. These factors are outside the control of the operating agency and if these factors were taken into account, it might be possible to show that agencies with seemingly lower performance metrics are actually operating more efficiently than others with higher metrics simply based on population and service area size. These potential factors/non-controllable data, as per TCRP Report 136, can be measured using the following data such as:

- Resident 2010 Census population

- Number of residents in service area age 65 and older

- Land area, square miles

- Road length, miles

- $\%$ road length miles $>=5 \%$ slope (as steep slopes create more wear on vehicles)

- $\%$ road length miles $>=10 \%$ slope

- $\%$ road length miles $>=15 \%$ slope

- Mean slope \%

- Total number of rail crossing in the service area

- Total number of intersections in the service area

- Median household income, in dollars, 2010

- Shape factor to assess the shape of the service area to determine the ease of offering service

The non-controllable data were further developed for use as performance measures, as shown in Table 3. 
TABLE 3.

Data Needed Further

Processing

\begin{tabular}{|l|l|}
\hline \multicolumn{1}{|c|}{ Variable } & \multicolumn{1}{c|}{ Type of Processing } \\
\hline Older adult, age 65 and older & Using access to determine the summation of age 65 and older \\
\hline Road length, miles & Using ArcGIS summation \\
\hline$\%$ road length miles $>=5 \%$ & $\begin{array}{l}\text { Using ArcGIS slope raster from DEM. Contour of slope raster, } \\
\text { summation of roadways intersect with }>=5 \%\end{array}$ \\
\hline$\%$ road length miles $>=10 \%$ & $\begin{array}{l}\text { Using ArcGIS slope raster from DEM. Contour of slope raster, } \\
\text { summation of roadways intersect with }>=10 \%\end{array}$ \\
\hline$\%$ road length miles $>=15 \%$ & $\begin{array}{l}\text { Using ArcGIS slope raster from DEM. Contour of slope raster, } \\
\text { summation of roadways intersect with }>=15 \%\end{array}$ \\
\hline Mean slope \% & Using ArcGIS slope raster from DEM. Mean of slope raster \\
\hline Road and rail intersections & Using ArcGIS, find number of roadways intersect with railways \\
\hline Intersections & $\begin{array}{l}\text { Exporting DBF from ArcGIS and opening table in Excel, count the } \\
\text { instances where common FNODE and TNODE appear without } \\
\text { duplicating same occurrence }\end{array}$ \\
\hline Shape factor (SF) & $\begin{array}{l}\text { Dissolving county boundaries by the boundary of transit system and } \\
\text { calculating SF that is equal to \{(perimeter/4) } / \text { (Area)\} }\end{array}$ \\
\hline
\end{tabular}

\section{Data Analysis}

When examining the systems, it was determined that whereas most systems operate over a single county service area, there are others that are operating in sub-county areas or multiple counties:

- Four locations operate in sub-county areas, either by serving only selected cities in the county or by serving only residents who live in the non-urban portion of a county.

- Three agencies serve multiple counties.

In an effort to remove bias from the results, a series of candidate systems was developed to test the effect of sub-county and multiple county results:

- 22 systems exclude sub-county, urbanized, and multi-county systems

- 26 systems exclude multicounty systems

- 25 systems exclude sub-county and urbanized county systems

The correlation and its P-values between factors and performance measures for the different sample sizes were determined. The P-value is the observed significance level of the test. If the observed significance level is less than the chosen significance level (alpha), then the researcher should reject the null hypothesis (no significant correlation) in favor of the alternative (a significant correlation). Otherwise, there is not enough evidence to reject the null hypothesis. Based on the results and to eliminate the differences in the extent and type of area covered by transit systems, it was decided to keep the sample size of 25 systems, eliminating the sub-county systems.

Furthermore, it was determined that the values of correlation between factors and the variables of performance measures improve when 25 systems were analyzed rather than 
total number of system in the state of 29 , mentioned in the data collection section. The following factors were identified that are correlated with the variables of PM and describe most of other factors such as population, land area, intersections, and shape factor that are also correlated with PM variables :

- Road length miles (RL miles) were correlated with all PM variables except passenger service hours and correlated with most of other factors (population, land area, intersections, and shape factor).

- \% road length miles $>=5 \%$ slope was correlated with operating and administrative costs and not explained by other selected factor. However, administrative cost does not include any maintenance cost and \% road length miles $>=5 \%$ slope was not considered a correlated factor with administrative cost.

The following factors were identified that are correlated with performance measures and describe most of other factors such as intersections and land area:

- $\%$ of residents in the service area age 65 and older was correlated with mileage utilization and not explained by other selected factor.

- RL miles were correlated with productivity and operating cost per passenger trip, and explains most other factors (land area and intersections). However, land area miles can explain the same number of other correlated factors. RL miles were selected because they show better correlation values with others.

To remove the correlation of variable issue, several of the equations were modified. Most of the PM values were unchanged after incorporating the division because of the presence of the same factor in numerator and denominator. The division tool was applied for correlated factors with PM variables regardless of sign of correlation.

Second, three of the performance measures correlated with the selected factors were divided by the corresponding factors to eliminate their influence from PM: productivity, operating cost per passenger trip, and mileage utilization.

Finally, it can be seen that there are performance measures (presented in Table 1 on the right side as equations) related to operating cost that do not have any correlation with any factor, whereas as a PM variable, operating cost is correlated with \% road length miles $>=$ $5 \%$ slope. So, it was necessary to combine the findings of the above two analyses, namely correlated factors in PM variables and correlated factors for performance measures, and can be presented as one Table 4, where the bold rows are from PM results and others are from PM variables results. The only exception is for operating cost per passenger trip, which includes correlated factors both from PM variable and PM analyses. 
TABLE 4. Equations after Incorporating Correlated Factors

\begin{tabular}{|c|c|}
\hline $\begin{array}{l}\text { Measures/ } \\
\text { Key Ratios }\end{array}$ & Equations \\
\hline Productivity & $\frac{\text { Passenger trips }}{\text { vehicle hour }} /_{\text {RL miles }}$ \\
\hline $\begin{array}{l}\text { Operating Cost } \\
\text { per Vehicle } \\
\text { Hour }\end{array}$ & $\frac{\text { Operating cost }}{\text { RL miles } * \% \text { RL miles }>=5 \% \text { slope }}+\frac{\text { Administrative cost }}{\text { RL miles }} / \frac{\text { Vehicle hours }}{\text { RL miles }}$ \\
\hline $\begin{array}{l}\text { Operating Cost } \\
\text { per Vehicle Mile }\end{array}$ & $\frac{\text { Operating cost }}{\text { RL miles } * \% \text { RL miles }>=5 \% \text { slope }}+\frac{\text { Administrative cost }}{\text { RL miles }} / \frac{\text { Vehicle miles }}{\text { RL miles }}$ \\
\hline $\begin{array}{l}\text { Operating Cost } \\
\text { per Passenger } \\
\text { Trip }\end{array}$ & $\frac{\text { Operating cost }}{\text { RL miles } * \% \text { RL miles }>=5 \% \text { slope }}+\frac{\text { Administrative cost }}{\text { RL miles }} / \frac{\text { Passenger trips }}{\text { RL miles }} /$ RL miles \\
\hline $\begin{array}{l}\text { Average } \\
\text { Passenger Trip } \\
\text { Length }\end{array}$ & Total passenger miles / Total number of passenger trips \\
\hline $\begin{array}{l}\text { Average Travel } \\
\text { Time }\end{array}$ & $\begin{array}{l}\text { Total passenger travel time } \\
\qquad \frac{\text { Total number of passenger trips }}{\text { RL miles }}\end{array}$ \\
\hline $\begin{array}{l}\text { Hourly } \\
\text { Utilization }\end{array}$ & Passenger hours $/ \frac{\text { Vehicle hours }}{\text { RL miles }}$ \\
\hline $\begin{array}{l}\text { Mileage } \\
\text { Utilization }\end{array}$ & $\frac{\text { Passenger miles }}{\text { Vehicle miles }} /_{\text {RL miles }}$ \\
\hline $\begin{array}{l}\text { Operational } \\
\text { Cost Recovery } \\
\text { Ratio }\end{array}$ & $\frac{\overline{\text { Revenue }}}{\text { RL miles }} / \frac{\text { Operating cost }}{\frac{\text { RL miles } * \% \text { RL miles }>=5 \% \text { slope }}{}}$ \\
\hline
\end{tabular}

\section{Results}

Original performance measures without incorporating any changes for correlation were given a ranking throughout the state based on best value. For example, if productivity or hourly utilization or mileage utilization or operational cost recovery ratio of any system had the highest value, that system was assigned as 1st rank. Performance measures related to operating cost, average time, or average length should have the lowest value assigned as 1st rank as the lower the operating cost or average time or length of a transit system, the better the system performs. After assigning the rank for each performance measure, the summation of ranks was again ranked to assess the overall performance of each system.

Performance measures based on updated PM variables were ranked individually, and aggregated rankings were done similarly. Likewise, aggregated ranking of performance measures were calculated based on combined findings that considered the modified equations of Table 4.

Examining the values for all agencies, essentially adding the ranking for the nine performance measures, creates a total statewide ranking. The following table (Table 5) shows 
the rankings from the original performance measures and from using the equations presented in Table 4 (combined updated measure), along with the change.

TABLE 5.

Statewide Rank and Change Associated with Difference

in PMs

\begin{tabular}{|c|c|c|c|}
\hline Agency & $\begin{array}{c}\text { Original } \\
\text { Rank }\end{array}$ & $\begin{array}{c}\text { Modified } \\
\text { Rank }\end{array}$ & Change \\
\hline A & 8 & 7 & +1 \\
\hline B & 24 & 14 & +10 \\
\hline C & 9 & 4 & +5 \\
\hline D & 6 & 23 & -17 \\
\hline E & 27 & 20 & +7 \\
\hline F & 7 & 3 & +4 \\
\hline G & 23 & 13 & +10 \\
\hline H & 19 & 11 & +8 \\
\hline I & 20 & 16 & +4 \\
\hline J & 29 & 28 & +1 \\
\hline K & 25 & 25 & +0 \\
\hline L & 11 & 12 & -1 \\
\hline M & 5 & 8 & -3 \\
\hline N & 16 & 21 & -5 \\
\hline O & 4 & 6 & -2 \\
\hline P & 12 & 17 & -5 \\
\hline Q & 10 & 10 & +0 \\
\hline R & 15 & 18 & -3 \\
\hline S & 28 & 29 & -1 \\
\hline T & 21 & 19 & +2 \\
\hline U & 22 & 22 & +0 \\
\hline V & 13 & 24 & -11 \\
\hline W & 2 & 2 & +0 \\
\hline X & 1 & 1 & +0 \\
\hline Y & 14 & 15 & -1 \\
\hline Z & 18 & 26 & -8 \\
\hline AA & 17 & 9 & +8 \\
\hline BB & 26 & 27 & -1 \\
\hline CC & 3 & 5 & -2 \\
\hline & & & \\
\hline & 25 & +1 \\
\hline
\end{tabular}

\section{Conclusions}

The main purpose of the study was to formulate a new methodology that eliminates the influences of uncontrollable factors, thus standardizing the performance measures defined in TCRP Report 136 to make a better comparison among different rural transit systems in Alabama. Existing measures were modified for comparison purposes in Alabama. After excluding correlated uncontrollable factors, it can be seen that the ranking of individual PM was changed. Sometimes, the lower rankings turn out to be the best 
ranking after standardization. The aggregated ranking also shows significant difference for aggregated existing and updated ranking. It can be concluded that this methodology provides a useful way to standardize the performance measures by eliminating the effects of uncontrollable factors such as different terrain, population, and road coverage conditions etc., and rank those by maintaining a fair scale of judgment. The final recommendation is to use this tool to make a fair individual or aggregated ranking of performance measures among different rural transit systems.

\section{References}

Allen, William G., and Frank Di Cesare. 1976. Transit service evaluation: preliminary identification of variables characterizing level of service. Transportation Research Record, 606: 41-47.

Arman, Mohammad, Samuel Labi, and Kumares C. Sinha. 2012. An assessment of the operational performance of public transit agencies using Data Envelopment Analysis (DEA) technique. Transportation Research Record, 2351: 30-37.

Bertini, Robert L., and Ahmed El-Geneidy. 2003. Generating transit performance measures with archived data. Transportation Research Record, 1841: 109-119.

Chu, Xuehao, Gordon J. Fielding, and Bruce W. Lamar. 1992. Measuring transit performance using Data Envelopment Analysis. Transportation Research Part A: Policy and Practice, 26: 223-229.

Cottrell, Wayne D., and Bill James. 2009. Performance measures for personal rapid transit. Proceedings of the 88th Annual Meeting of the Transportation Research Board, Washington, D.C.

Ellis, Elizabeth, and Brian McCollom. 2009. TCRP Report 136, Guidebook for Rural Demand Response Transportation: Measuring, Assessing, and Improving Performance. Washington DC: Transportation Research Board.

Ferronatto, Luciana Guadalupe, Luis Antonio Lindau, and Flavio Sanson Fogliatto. 2009. Comparison of public transportation efficiency indices based on data envelopment analysis and principal component analysis. Proceedings of the 88th Annual Meeting of the Transportation Research Board, Washington, DC.

Fielding, Gordon J., and Shirley C. Anderson. 1983. Public transit performance evaluation: Application to Section 15 Data. Transportation Research Record, 947: 1-7.

Fu, Liping, Jingtao Yang, and Jeff Casello. 2007. Quantifying the technical efficiency of paratransit systems using the Data Envelopment Analysis method. Transportation Research Record, 2034: 115-122.

Gan, Albert C., Ike Ubaka, and Fang Zhao. 2002. Integrated National Transit Database analysis system. Transportation Research Record, 1799: 78-88.

Institute, Carsey. 2006. Demographic trends in rural and small town America. University of New Hampshire, Durham. 
Karlaftis, Matthew G., and Kumares C. Sinha. 1997. Performance impacts of operating subsidies in the paratransit sector. Transportation Research Record, 1571: 75-80.

Kittelson \& Associates, Inc., Parsons Brinckerhoff, Inc. KFH Group, Texas A\&M Transportation Institute, and Arup. TCRP Report 165: Transit Capacity and Quality of Service Manual. Washington, DC: Transportation Research Board, 2013.

Kosky, Scott. 2007. Performance evaluation for rural transit systems. Rural Transit Assistance Program, Columbia, MO.

Marshment, Richard S. 1998. Assessment of state procedures for allocating Section 5311 subsidies to rural public transit operators. Transportation Research Record, 1623: 63-67.

Radow, Laurel J., and Chris Winters. 2011. Rural transit performance measurement. http:// www.ctaa.org/webmodules/webarticles/articlefiles/Rural_Transit_Performance_ Measurement.pdf (accessed November 21, 2011).

Reilly, Jack, Edward Beimborn, and Robert Schmitt. 1998. Transit performance measurement. Adapted from NTI course "Improving Transit System Performance: Using Information Based Strategies," developed at University of Wisconsin-Milwaukee, 1996-98. Albany, N.Y..

Ryus, Paul, et al. 2011. Development of the TCRP G-11 Transit agency peer-grouping methodology. Proceedings of the 90th Annual Meeting of the Transportation Research Board, Washington, DC.

Sousa, Paul, and Eric J. Miller. 2005. Performance-driven transit funding model. Transportation Research Record, 1927: 73-81.

Stephanedes, Y. J. 1979. Performance indicators and policy evaluation in rural transit. Ph.D. dissertation, Dartmouth College, Hanover, New Hampshire.

\section{About the Authors}

Dr. Michael Anderson (andersmd@uah.edu) works as an Associate Professor in the Department of Civil and Environmental Engineering at the University of Alabama in Huntsville. His areas of interest include transportation planning/modeling, freight planning, traffic simulation, GIS application, traffic safety and development of decision support tools.

TAHMINA KHAN (tk0002@uah.edu) is a graduate student in the Civil and Environmental Engineering Department at the University of Alabama in Huntsville. 